Ophthalmologica

\title{
Downregulation of Serum IGF-1 for Treatment of Early Worsening of Diabetic Retinopathy: A Long-Term Follow-Up of Two Cases
}

\author{
Ernst Chantelau ${ }^{a}$ Rolf Meyer-Schwickerath ${ }^{c}$ Karsten Klabe ${ }^{b}$

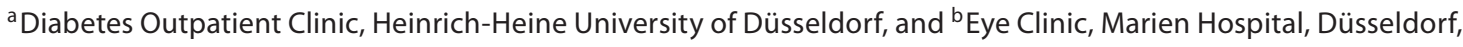 \\ 'Practice of Ophthalmology, Bocholt, Germany
}

\section{Key Words}

Diabetic retinopathy $\cdot$ Growth factors · Insulin therapy

\begin{abstract}
In 2003, we reported on 2 cases of nonproliferative and proliferative diabetic retinopathy, subsequent to $\mathrm{HbA1c}$ reduction by intensive insulin therapy (so-called early worsening of diabetic retinopathy). This acute condition could partly be reversed by discontinuation of intensive insulin therapy, whereby glycemia increased and serum IGF-1 concentration decreased [Ophthalmologica 2003;217:373-377]. On review 7 years later, both type-2 diabetic patients were on insulin therapy but had failed to achieve good glycemic control. One patient had mild background retinopathy on both eyes, with visual acuity of 1.0 and 0.7 after cataract extraction plus intravitreal triamcinolone injection. The 2 nd patient was blind in one eye from secondary glaucoma due to vitrectomy and silicone oil filling; the fellow eye displayed residual retinal neovascularization with a hyaloid membrane and a visual acuity of 0.5 . Hence, early worsening as opposed to late worsening of diabetic retinopathy seems to benefit from therapeutic suppression of growth factor action.
\end{abstract}

Copyright $\odot 2009$ S. Karger AG, Basel

\section{Introduction}

Early worsening (EW) of diabetic retinopathy can be stimulated by upregulation of serum IGF-1 concentration through intensified insulin therapy $[1,2]$. Reversion of this acute retinal pathology may, thus, be achieved by re-lowering serum IGF-1 [3, 4]. In 2003, a preliminary proof of this concept was provided by 2 patients with type 2 diabetes mellitus who had experienced EW and who were subsequently advised to discontinue intensive insulin therapy [4]. Here, we present an extended follow-up of these patients, based on the hospital records and a personal examination in 2008.

\section{Case Reports}

Case 1

This female patient was born in 1974 and was diagnosed with type 2 diabetes mellitus at the age of 13 . She did not receive insulin treatment until 2000, when an eye examination did not show any pathology: vision was normal and diabetic retinopathy was absent. Intensive insulin therapy was commenced, decreasing her HbA1c (normal range 4.6-6.1\%) from 11.9 to $6.7 \%$ within 8 weeks. Already after 4 weeks of insulin therapy, Snellen visual acuity had dropped from 1.0 to 0.2 due to macular edema accompanied by severe blot hemorrhages in all 4 quadrants (severe nonproliferative diabetic retinopathy, NPDR) and diffuse cataract. EW was 

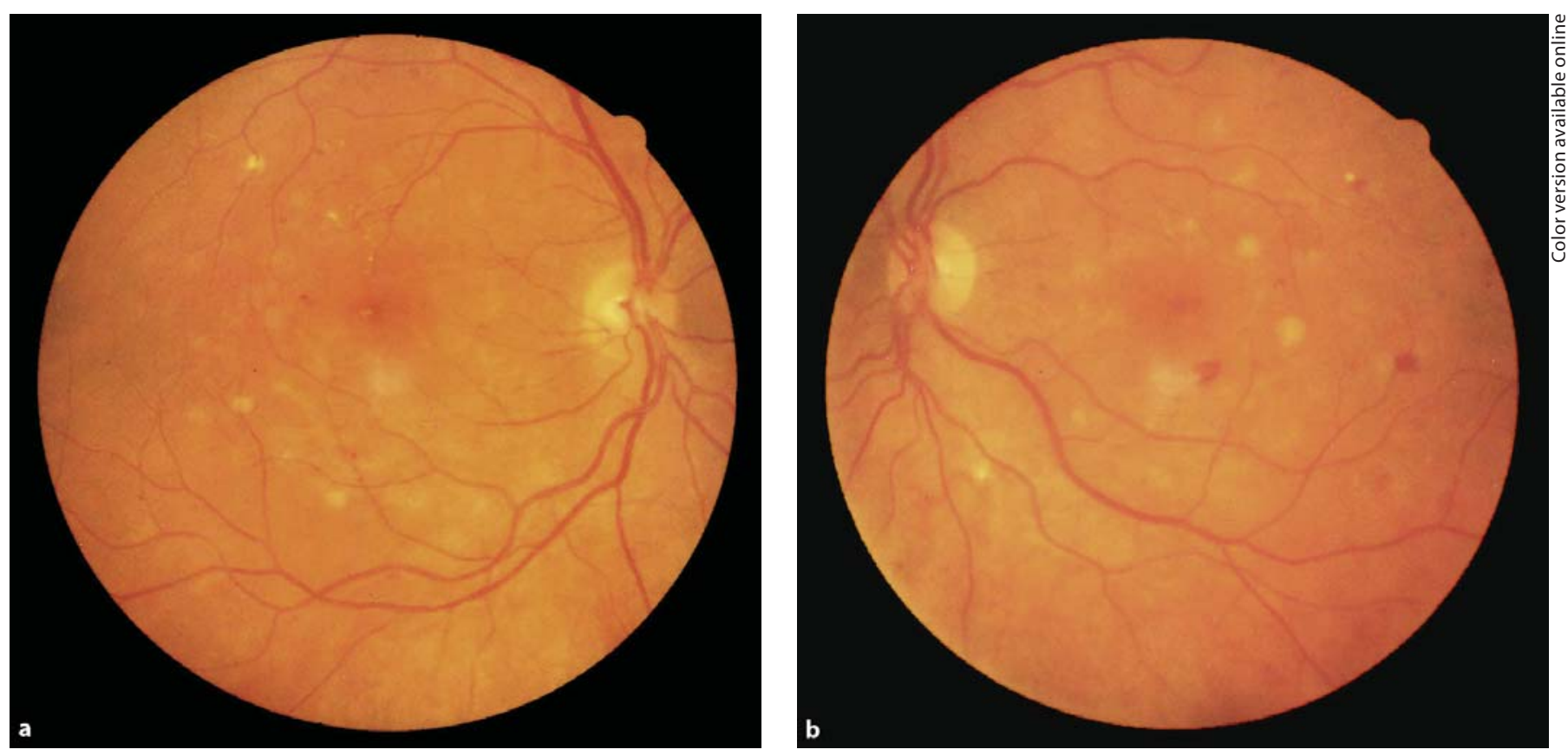

Fig. 1. Eye fundi of patient 1,7 years after successful treatment of EW of diabetic retinopathy and 1 year after cataract extraction. Moderate NPDR, focal laser scars. Visual acuity was 1.0 in the right eye (a) and 0.7 in the left eye (b).

diagnosed, and focal central laser coagulation was performed without much effect. Subsequently, insulin treatment was discontinued. Macular edema and hemorrhages resolved, while HbAlc concentration increased from 6.7 to around $10 \%$ (equivalent to an average blood glucose concentration of $250 \mathrm{mg} / \mathrm{dl}$ ), and serum IGF-1 concentration decreased from 387 to around $280 \mathrm{ng} / \mathrm{ml}$. Visual acuity improved to 0.8 on both eyes. In 2002, her HbAlc was maintained at $9.6 \%$, and visual acuity had remained at 0.8 . In 2001, incipient nephropathy was present, with microalbuminuria of $73 \mathrm{mg} / \mathrm{l}$ (normal $<20 \mathrm{mg} / \mathrm{l}$ ). However, albuminuria increased to $658 \mathrm{mg} / \mathrm{l}$ in 2002, and blood pressure also increased, requiring antihypertensive medication, while serum creatinine remained normal $(<0.9 \mathrm{mg} / \mathrm{dl})[4]$.

In 2008, the patient could be reassessed 7 years after experiencing EW. Diabetes duration was now 21 years. Her case history revealed that she had resumed insulin therapy in 2004 after 36 months of insulin withdrawal. Her body weight had increased from 88 to $102 \mathrm{~kg}$. Diabetic nephropathy, confirmed by biopsy in 2005, had caused chronic kidney failure and renal anemia (serum creatinine concentration increased to $1.9 \mathrm{mg} / \mathrm{dl}$ ). Erythropoietin injections had been prescribed. Blood pressure control was poor (160/90 mm Hg), as was blood glucose control (HbAlc was repeatedly around $12 \%$, equivalent to an average blood glucose concentration of around $320 \mathrm{mg} / \mathrm{dl}$ ). There was no indication of peripheral neuropathy.

In 2006, the cataracts had reduced visual acuity to 0.4 in both eyes. Without improving glycemic control [5], bilateral cataract extraction with intraocular lens implantation was performed successfully by phakoemulsification plus intravitreal injection of $4 \mathrm{mg}$ triamcinolone acetonide. Postoperatively, retinopathy re- mained unaffected (moderate NPDR), and visual acuity normalized.

On her last visit in 2008, blood pressure was 160/90 mm Hg, blood glucose was $153 \mathrm{mg} / \mathrm{dl}, \mathrm{HbAlc}$ was $12.2 \%$ (equivalent to an average glycemia of about $330 \mathrm{mg} / \mathrm{dl}$ ), serum creatinine was 2.5 $\mathrm{mg} / \mathrm{dl}$, and IGF-1 was $169 \mathrm{ng} / \mathrm{ml}$, respectively. She was preparing for hemodialysis. She had full visual acuity (right eye 1.0; left eye 0.7 ) and moderate NPDR with few laser scars and blot hemorrhages (fig. 1).

\section{Case 2}

This patient was a woman born in 1960 who was diagnosed with type 2 diabetes mellitus at the age of 23 . She did not receive insulin treatment until 2000, when intensive insulin therapy was commenced, decreasing her HbAlc from 9.9 to $6.8 \%$ within 24 weeks. Immediately prior to this, mild NPDR had been diagnosed and visual acuity was 1.0 on both eyes. Within 8 weeks of insulin therapy, Snellen visual acuity had dropped to 0.6 due to severe NPDR with cystoid macular edema. Despite focal laser coagulation, NPDR progressed to severe proliferative diabetic retinopathy in both eyes after 16 weeks of insulin therapy. Panretinal laser coagulation was applied. Visual acuity decreased to 0.5 on both eyes. After 12 months of insulin treatment, acute subhyaloid bleeding occurred in the right eye, requiring vitrectomy with silicone oil filling in October 2001. At this stage, EW was diagnosed and insulin therapy was withdrawn, whereby visual acuity improved to 0.8 , and proliferations partly regressed in the left eye. In the right eye, cataract developed, reducing the visual acuity to 0.3. Insulin withdrawal increased the HbAlc concentration to around $12 \%$ (equivalent to an average blood glucose concentra- 
tion of $320 \mathrm{mg} / \mathrm{dl}$ ) and decreased serum IGF-1 concentration from 376 to around $247 \mathrm{ng} / \mathrm{ml}$. In 2002, HbA1c was $11.1 \%$, and visual acuity was maintained at 0.8 (left eye), and 0.3 (right eye), respectively. In 2001, incipient nephropathy had been present with microalbuminuria of $50 \mathrm{mg} / \mathrm{l}$; albuminuria improved to $14 \mathrm{mg} / \mathrm{l}$ in 2002. However, peripheral polyneuropathy progressed and acute Charcot foot occurred [4].

In 2008, the patient could be reassessed 8 years after experiencing EW and 25 years after diagnosis of diabetes, respectively. According to her case history, she had resumed insulin therapy in 2002, after 12 months of insulin withdrawal, and had achieved HbA1c concentrations of only $9.2-10 \%$ (equivalent to an average glycemia of 220-250 mg/dl). Concomitantly, serum IGF-1 had decreased to $189 \mathrm{ng} / \mathrm{ml}$ in 2003. Albuminuria and serum creatinine had remained normal ( $<20$ and $<0.9 \mathrm{mg} / \mathrm{dl}$, respectively), as had blood pressure without antihypertensive medication. Peripheral neuropathy was unchanged. She frequently had sustained pressure ulcers at the Charcot foot, although orthopedic footwear had been provided. In 2004, ovarial and endometrium cancer was detected and cured by hysterectomy and radiation therapy.

In 2003, bilateral cataract was present. However, cataract extraction with intraocular lens implantation was performed only in the right eye in 2004, leading to secondary glaucoma due to silicone oil dispersion in 2006. Trabecular aspiration and cyclophotocoagulation could not prevent this eye from getting blind. In the fellow eye, focal laser coagulation had been carried out several times; the cataract was left untouched.

On her last visit in 2008, blood pressure was 137/86 mm Hg, blood glucose was $135 \mathrm{mg} / \mathrm{dl}$, HbAlc was $8.4 \%$ (equivalent to an average glycemia of approximately $200 \mathrm{mg} / \mathrm{dl}$ ), serum creatinine was $0.9 \mathrm{mg} / \mathrm{dl}$, and serum IGF- 1 was $120 \mathrm{ng} / \mathrm{ml}$. There was no active foot ulcer. The right eye was blind. On the left eye, displaying advanced cataract as well as residual neovascularizations at the disc and a posterior hyaloid membrane (fig. 2), visual acuity was 0.5 .

\section{Discussion}

The present cases demonstrate that systemic downregulation of serum IGF-1 is an effective and durable supportive treatment of EW, particularly when applied in early, i.e., nonproliferative stages of EW. Macular edema and retinal hemorrhages responded favorably to IGF-1 downregulation (both cases), whereas neovascularization did not (case 2). IGF-1 downregulation through poor diabetes control was maintained during the entire followup period, and hence there was no relapse of EW.

Discontinuation of intensive insulin therapy and worsening of glycemic control may cause IGF-1 downregulation, as in our cases. Systemic anticancer chemotherapy [6] or octreotide administration [3] may have similar effects in florid diabetic retinopathy or EW. However, either strategy may pose long-term hazards to the patients. Therefore, local inhibition of IGF-1 activity (or



Fig. 2. Left eye fundus of patient 2,7 years after successful treatment of EW of diabetic retinopathy. Residual proliferative diabetic retinopathy with neovascularization, a posterior hyaloid membrane, and panretinal laser coagulation scars. Visual acuity was 0.5 .

IGF-1-mediated VEGF activity [7]) by intravitreal injection of triamcinolone or VEGF inhibitors is currently being investigated for therapeutic purposes [8-10]. Another means to treat EW may be intensive laser coagulation, as has been employed with some success in the Diabetes Control and Complications Trial (DCCT). In this randomized controlled trial involving 1,441 type 1 diabetic patients, EW was treated by laser coagulation, while intensive insulin therapy, aiming at $\mathrm{HbAlc}$ levels $<7 \%$, was not discontinued. As a result, EW improved only in half of the patients [11].

EW has to be discerned from the chronic late worsening (LW) of diabetic retinopathy, which has traditionally been viewed as the typical natural course of diabetic retinopathy. According to this view, LW develops gradually as a consequence of the cumulative glycemic load the retina is exposed to over years. However, the DCCT has revealed that only $11 \%$ of the entire diabetic retinopathy risk in that study was explained by the total glycemic exposure (i.e., the HbAlc values multiplied by the duration of diabetes), whereas $89 \%$ of the risk was explained by unknown risk factors independent of HbAlc [12]. 
We suggest that apart from genetic factors (which may account for $25 \%$ of the retinopathy risk in type 2 diabetes [13]) and stable hyperglycaemia [12], abrupt upregulation of serum IGF-1 through intensive insulin therapy (and subsequent acute EW [1]) might be considered another risk factor for LW. This hypothesis is consistent with the DCCT findings, demonstrating severe LW in 58\% of cases with previous EW, compared to $26 \%$ of cases without previous EW [11]. Acute EW seems, thus, particularly deleterious to the chronic process of LW of diabetic retinopathy.
In conclusion, the reported cases show a beneficial effect of transient suppression of serum IGF-1 concentrations (achieved by discontinuation of intensive insulin therapy) in EW. In addition to standard laser coagulation, this strategy seems to be particularly useful during EW with NPDR. Controlled trials are mandatory to firmly establish the therapeutic potential of (local or systemic) targeting growth factor action in EW.

\section{References}

1 Chantelau E: Evidence that upregulation of serum IGF-1 concentration can trigger acceleration of diabetic retinopathy. Br J Ophthalmol 1998;82:725-730.

2 Gomez-Peralta F, Pujante P, Abreu C, Santos E, Garcia-Layana A, Salinas A, Varo N: Retinal thickness after insulin therapy initiation in patients with type 2 diabetes. An optical coherence tomography (OCT) based study (abstract). Diabetologia 2007;50(suppl 1): S448.

3 Chantelau E, Frystyk J: Progression of diabetic retinopathy during improved metabolic control may be treated with reduced insulin dosage and/or somatostatin analogue administration - a case report. Growth Horm IGF Res 2005;15:130-135.

4 Chantelau E, Meyer-Schwickerath R: Reversion of 'early worsening' of diabetic retinopathy by deliberate restoration of poor metabolic control. Ophthalmologica 2003;217: 373-377.
5 Suto C, Hori S, Kato S, Muraoka K, Kitano S: Effect of perioperative glycemic control in progression of diabetic retinopathy and maculopathy. Arch Ophthalmol 2006;124: 38-45.

6 Varughese G, Rao P, Barton D, Warner D: Changes in diabetic retinopathy noticed after chemotherapy for duodenal carcinoma. Br J Diabetes Vasc Dis 2004;4:206-208.

-7 Chantelau E, Kimmerle R, Meyer-Schwickerath R: Insulin, insulin analogues and diabetic retinopathy. Arch Physiol Biochem 2008;114:54-62.

-8 Simo R, Hernandez C: Intravitreous antiVEGF for diabetic retinopathy: hopes and fears for a new therapeutic strategy. Diabetologia 2008;51:1574-1580.

$>$ Shimura M, Nakazawa T, Yasuda K, Shiono T, Iida T, Sakamoto T, Nishida K: Comparative therapy evaluation of intravitreal bevacizumab and triamcinolone acetonide on persistent diffuse diabetic macular edema. Am J Ophthalmol 2008;145:854-861.
10 Jonas JB: Intravitreal triamcinolone acetonide for diabetic retinopathy. Dev Ophthalmol 2007;39:96-110.

$>11$ The Diabetes Control and Complications Trial Research Group: Early worsening of diabetic retinopathy in the Diabetes Control and Complications Trial. Arch Ophthalmol 1998;116:874-886; Erratum: Arch Ophthalmol 1998;116:1469.

12 Lachin JM, Genuth S, Nathan DM, Zinman $\mathrm{B}$, Rutledge BN, for the DCCT/EDIC Research Group: Effect of glycemic exposure on the risk of microvascular complications in the Diabetes Control and Complications Trial - revisited. Diabetes 2008;57:9951001.

13 Arar NH, Freedman BI, Adler SG, et al: Heritability of the severity of diabetic retinopathy: the FIND-Eye Study. Invest Ophthalmol Vis Sci 2008;49:3839-3845. 